\title{
Juegos de lenguaje sociales y palabras que dañan. Un estudio sobre la interpretación aplicada de la obra del segundo Wittgenstein
}

\author{
Isabel G. Gamero Cabrera*
}

\begin{abstract}
Resumen: En este artículo voy a profundizar en una interpretación aplicada de la obra del segundo Wittgenstein, propuesta por José Medina, Miranda Fricker y Peg O'Connor, entre otros. Estos autores equiparan juegos de lenguaje y formas de vida, entienden las reglas de los juegos como normas sociales y trasladan la argumentación del filósofo vienés a un ámbito sociopolítico. Concretamente, José Medina propone un argumento en oposición a los juegos de lenguaje sociales, que es la versión social al argumento de Wittgenstein en oposición a los juegos de lenguaje privados. En segundo lugar, analizaré dos casos: las distintas denominaciones de los indios huicholes y el uso del plural inclusivo por parte de algunos feminismos. Lo más interesante de estos dos casos es que estos grupos proponen significados privados o usos del lenguaje que sólo parecen ser válidos para ellos. Preguntaré si estos usos se pueden entender como juegos de lenguaje sociales y ser criticados desde los argumentos de Medina. Este estudio de casos servirá para evaluar la adecuación, validez y límites de esta interpretación de la obra de Wittgenstein.
\end{abstract}

Palabras clave: Wittgenstein, juego de lenguaje, reglas, huicholes, plural inclusivo

Abstract: The main aim of this paper is to study in depth an applied interpretation of the later Wittgenstein's work, developed by José Medina, Miranda Fricker and Peg O'Connor, among other authors. They equate the concepts of "language-games" and "forms of life", understand the rules of the games as social norms and place Wittgenstein's arguments in the socio-political field. Specifically, José Medina coins an argument against social language-games, which is the social version of Wittgenstein's argument against private language-games. Secondly, I will analyse two cases: the different denominations of the Huichol Indians and the uses of the inclusive plural

* Licenciada en Filosofía y Periodismo, Máster en Filosofía y en Antropología Social y Cultural, y Doctora en Filosofía por la Universidad Complutense de Madrid. Impartió clases en la Universidad Complutense de Madrid y en la Universidad Autónoma de Nayarit (Tepic, México). Actualmente es becaria postdoctoral del CONICET en el Instituto de Investigaciones en Humanidades y Ciencias Sociales de la Universidad Nacional de la Plata. Dirección electrónica: isgamero@gmail.com 
proposed by some feminists. The main interest of these cases is that both groups propose private meanings or particular uses of some terms, which seems to be valid just for them. I will ask whether these uses can be understood as social language-games and thus be criticised by Medina's arguments. This case analysis is addressed to evaluate the accuracy, validity and the limits of this interpretation of Wittgenstein's work.

Key words: Wittgenstein, language-games, rules, Huichol Indians, inclusive plural

\section{Presentación de la comprensión del lenguaje del segundo Wittgenstein}

\subsection{Los juegos y las reglas}

En el inicio de sus Investigaciones, Wittgenstein contempla la posibilidad de entender los juegos de lenguaje como formas de vida. Sostiene, por ejemplo, que "imaginar un lenguaje significa imaginar una forma de vida" (IF 19), así como que "la expresión 'juego de lenguaje' debe poner de relieve (...) que hablar el lenguaje forma parte de una actividad o de una forma de vida"1 (IF 23). Estos pasajes han sido interpretados de forma muy distinta por diferentes autores ${ }^{2} \mathrm{y}$ existe una amplia polémica sobre la pertinencia de igualar el concepto de juego de lenguaje con el de vidas humanas y trasladar las reflexiones de este autor de un ámbito más lingüístico y lógico (donde parecía ubicarse su obra) a uno político o social. ${ }^{3}$

En este artículo, voy a aceptar esta equiparación, siguiendo las obras de

\footnotetext{
${ }^{1}$ Wittgenstein, Ludwig, Investigaciones Filosóficas, Barcelona, Crítica, 1988, aforismo 23. En lo que sigue, citaré esta obra, en el cuerpo del texto, con la abreviatura "IF", seguida del número del aforismo correspondiente.

2 Puede leerse una exhaustiva revisión de todas las menciones de "forma de vida" (Lebensform) en los escritos de Wittgenstein y sus distintas comprensiones en Majetschak, Stefan: "Forms and Patterns of Life: A Reassessment of a So-Called 'Basic Concept' in the Late Philosophy of Wittgenstein" en Marques y Venturinha (eds.), Wittgenstein on Forms of Life and the Nature of Experience, Berna, Peter Lang, 2010, pp. 7596. Véanse especialmente las páginas 86-94 de ese texto.

${ }^{3} \mathrm{Si}$ se desea conocer algunas de las críticas que ha recibido esta interpretación política de la obra de Wittgenstein y parte de la polémica que levantó, puede consultarse Crary, Alice: "Wittgenstein's Philosophy in Relation to Political Thought", en Crary (ed.), The
} 
José Medina, Peg O'Connor y Miranda Fricker, para evaluar hasta qué punto puede ser una herramienta teórica adecuada para analizar y tratar de solucionar algunas problemáticas sociales, como las discriminaciones que padecen algunas minorías. Sin embargo, antes de comenzar con el análisis de casos, y con independencia de si se admita o no la equiparación entre juegos de lenguaje y forma de vida, voy a describir algunos rasgos de la comprensión del lenguaje del segundo Wittgenstein para asentar el marco teórico.

En su segunda etapa (y a diferencia de lo que mantuvo en la primera), Wittgenstein considera que la relación entre palabras y cosas no es exclusivamente referencial y ostensiva, como si con las palabras designásemos meramente los objetos que nos rodean. Esta comprensión del lenguaje, que Wittgenstein atribuye a Agustín de Hipona (IF 1) es adecuada solo para los sustantivos y no tiene en cuenta que todas las demás clases de palabras no son tan fácilmente designables y están ligadas a acciones humanas (como verbos, adverbios, adjetivos y pronombres, IF 8, 9). Esto es, un niño no aprende el término "vaso" porque alguien lo señale, de modo ostensivo, y diga "vaso"; sino que lo incorpora a su vocabulario cuando alguien le dice: "Tráeme ese vaso" o "Ten cuidado, que vas a romper el vaso" y estas palabras se acompañan de ciertas actitudes o gestos. El niño va interiorizando estos usos del lenguaje, no como nombres separados que pueda señalar, sino como usos compartidos y ligados a prácticas (IF 6-9). Entonces, según Wittgenstein, el significado ya no es exclusivamente referencial, sino que, en la mayor parte de los casos, se trata de los usos que los hablantes dan a los términos en los juegos de lenguaje (IF 43). Los significados ya no serán solamente lo que refieren las entradas de los diccionarios, sino las prácticas compartidas y continuadas en grupos humanos.

Para acentuar esta comprensión, Wittgenstein acuña el concepto "juego de lenguaje", cuya primera definición es "el todo formado por el lenguaje y las acciones con las que está entretejido" (IF 7) y que, en ocasiones (y con las controversias interpretativas ya mencionadas), identifica con las formas de vida. Lo que destaca de los juegos es que están compuestos por reglas que necesitan seguimiento constante y continuado y grupal. Esto es: nadie puede seguir una regla una sola vez, en solitario, ya que los procesos de

New Wittgenstein, Londres, Routledge, 2000, pp. 118-141. 
seguimientos de reglas son costumbres, usos o instituciones (IF 199), que necesitan una cierta regularidad para su funcionamiento (IF 207). ¿Cuáles y cómo son entonces las reglas de los juegos?

Siguiendo la comprensión amplia del lenguaje que desarrolla en su segunda etapa, Wittgenstein rechaza la posibilidad de dar una definición única o general: no existe un caso único o ejemplo paradigmático de lo que sea un "juego", sino que son diferentes sistemas, con distintas reglas y distintas finalidades. No parece haber nada en común a todos los juegos que haga que empleemos la misma palabra para nombrarlos así, sino que "están emparentados entre sí de muchas maneras diferentes" (IF 65), formando "una complicada red de parecidos que se superponen y entrecruzan" (IF 66), de la que no podemos decir que haya un rasgo común o propiedad que los defina a todos, sino sólo unos "parecidos de familia" (IF 67), cambiantes y variables. En cualquier caso, si algo hubiera que destacar de las reglas de los juegos es que se relacionan con las prácticas humanas y un cierto dominio de una técnica (IF 199).

Wittgenstein da ejemplos de distintos juegos y sus reglas, insistiendo en que no hay un caso general que los abarque a todos. Se refiere así a procesos de seguimiento de secuencias matemáticas (IF 143ss.); juegos, como el ajedrez (IF 197); reglas lingüísticas o gramaticales (IF 8,9) o las pautas que siguen los componentes de una comunidad cuando cumplen órdenes (IF 206). Todos comparten los rasgos generales ya destacados: son procesos continuados en un tiempo concreto, se relacionan con una práctica, compartida por un grupo y presentan ciertas prohibiciones y ciertas concesiones.

\subsection{E1 argumento en oposición al juego de lenguaje privado}

Otra de las consecuencias de esta comprensión práctica y compartida de los juegos es lo que se ha llamado el argumento en oposición al juego de lenguaje privado, que Wittgenstein expone en sus Investigaciones (IF 240 passim) y que posteriormente ha sido desarrollado por algunos de sus intérpretes. ${ }^{4}$

\footnotetext{
${ }^{4}$ El que denominó a esta explicación el "argumento del juego de lenguaje privado" fue Saul Kripke en Wittgenstein on Rules and Private Language, Oxford, Basil Blackwell, 1985.
} 
Según este argumento, los usos del lenguaje son compartidos y nadie puede, por separado, crear un lenguaje propio o tener significados completamente privados, que sean incomprensibles para los demás hablantes de ese juego de lenguaje.

Esto es, para Wittgenstein alguien puede hablar consigo mismo, darse órdenes o ánimos, murmurar para sí, hacer chistes o bromas privadas. Estos usos son válidos y posibles, se dan en nuestros lenguajes habituales, pero nunca será completamente privados, incomunicables o incomprensibles para otras personas, ya que quien habla consigo mismo solo puede hacerlo porque ya ha aprendido un lenguaje con anterioridad, en una comunidad de hablantes y por este motivo ya conoce los procedimientos de dar órdenes, animar, hablar, hacer chistes (IF 243). Lo realmente difícil (imposible, según Wittgenstein) sería hacer cualquiera de estas acciones lingüísticas sin haberlas aprendido antes, sin haber tenido nunca contactos con otros seres humanos, sus reglas o sus lenguajes. ${ }^{5}$

Aquí se abren las clásicas preguntas sobre si Robinson Crusoe o un niño salvaje, criado en la selva por lobos, podrían tener un lenguaje privado. En el caso de Robinson está claro: tendría lenguaje porque ya aprendió la lengua materna en su infancia en Inglaterra y esto le permite hablar solo, con Viernes

Aunque explicaré este argumento con mis propias palabras en esta sección, puede leerse una buena exposición del mismo en el artículo de Alfonso García Suárez: "Wittgenstein y la idea de un lenguaje privado" (Daimon, Vol. 2, 1990, pp. 87-98). Otro artículo interesante para conocer este argumento y los debates sobre sus interpretaciones es "Los argumentos del lenguaje privado. Notas para la reconstrucción de una controversia” de Pedro Karczmarczyk (Diálogos, Vol. XLIV, No 92, 2012, pp. 73-124)

${ }^{5}$ Un elemento que Wittgenstein no contempló en este escenario, pero que quisiera destacar es la enorme dificultad que supondría que una persona creciera completamente sola y aislada, sin relación con nadie más. Más que preguntarnos si tendría o no lenguaje, habría que preguntar cómo pudo haber sobrevivido. Los experimentos mentales de la filosofía resultan imprescindibles para continuar pensando, pero no deberían ocultar la necesidad de cuidados, alimentación y acompañamiento que resulta necesaria para sobrevivir ya que, en caso contrario, se corre el riesgo de dar una imagen poco realista y distorsionada de lo que significa ser humano. Se puede leer más al respecto en Seyla Benhabib, Situating the Self, Cambridge, Polity Press, 1992. 
o con los árboles. Pero éste no sería un lenguaje privado, sino un lenguaje en soledad; si llegaran otros náufragos a la isla, Robinson podría hablar con ellos. En el caso del hombre de las cavernas (se trata de un ejemplo de Wittgenstein) o alguien criado en la selva, esta persona tendría otras reglas, otros usos del lenguaje, distintos a los nuestros, pero los seguiría teniendo, ya que ha crecido en una comunidad (sea de otros homínidos, sea de otros mamíferos) y, de alguna forma, quizás no comprensible para nosotros actualmente, esta persona se relacionaría y se entendería con los suyos. Cabría decir que tendría sus propios juegos de lenguaje, con sus propios significados y usos compartidos, no privados. De nuevo, cabe destacar que la vida en común y los significados y las prácticas compartidas resultan indispensables, según este punto de vista, para adquirir un lenguaje y vivir con otros. ${ }^{6}$

Ahora bien, Wittgenstein baraja la posibilidad de que se dé un juego de lenguaje privado, cuando una persona adulta, que ya maneja correctamente un lenguaje, decide crear otro distinto, solo para él. Por ejemplo, esta persona podría entender que su dolor es sólo suyo, incomunicable y que no lo puede sentir nadie más (IF 253) y podría crear un código para referirse a sus sensaciones y anotarlas en un cuaderno, con una notación que no sería comprensible para nadie más (IF 243-246). Como respuesta a esta posibilidad, Wittgenstein insiste en su crítica a la comprensión referencial del lenguaje ya descrita: ni una sensación ni un dolor son objetos que podamos aislar y señalar por separado, de modo ostensivo, sino que tanto su padecimiento como su expresión están ya imbricados con una serie de gestos y actitudes, compartidos por una comunidad de hablantes y se han aprendido así (IF 256). En este punto, y en lo que muchos intérpretes han definido como el naturalismo del segundo Wittgenstein, ${ }^{7}$ este autor también sostiene que las sensaciones como el dolor o

${ }^{6}$ Las referencias de Wittgenstein a Robinson se encuentran en el ítem 116, p. 117 (1 de septiembre de 1937), Band. XII: Philosophische Bemerkungen y en el ítem 124, p. 221 (3 de julio de 1944) del Nachlass. Las del hombre de las cavernas en el ítem 136, p. 141b (23 de enero de 1948), Band $Q$ y en el ítem 164, p. 123 (1 de enero de 1941) Taschennotizbuch. Todas estas citas se pueden consultar en el Nachlass: Text and Facsimile Version. Bergen Electronic Edition, Oxford, Oxford UP, 2000)

${ }^{7} \mathrm{El}$ primer autor que destacó este naturalismo fue John F. M. Hunter en su artículo "Forms of Life' in Wittgenstein's Philosophical Investigations" (American Philosophical Quarterly, Vol. 5.4. Octubre 1968, pp. 233-243). Más recientemente lo ha hecho Moyal- 
la alegría están conectadas con "manifestaciones naturales" de los seres humanos (IF 257), como expresiones faciales, gestos o ademanes. Estos gestos reflejan o muestran una sensación, incluso sin necesidad de palabras, ya que en el caso de que no supiésemos la palabra que se usa para decir dolor en una lengua desconocida, nos podríamos entender con mímica, haciendo el gesto de dolor que compartimos (IF 256-257).

Ahora bien, continúa Wittgenstein, ¿no podría darse la posibilidad de alguien, como un genio poco empático ${ }^{8}$ que vive fuera de todas las comunidades humanas, no conoce las expresiones faciales para expresar dolor y pudiera inventar un término para referir a una sensación, completamente suya, que no tiene nadie más?

Según Wittgenstein, aunque esto pueda ser plausible, en realidad, en el uso práctico del lenguaje, no podríamos llegar a entender a este genio. También habría que preguntar qué finalidad o uso tendría este término inventado, con qué práctica, actitud o gesto humano se relacionaría o para qué serviría.

Como respuesta a estas cuestiones, el autor continúa manteniendo que este uso aislado e incomunicable, de una persona sola, probablemente no tendría ninguna aplicación, ya que los usos del lenguaje, o bien son compartidos y transmisibles, o bien, es como si no existieran. (IF 257). E ilustra esta dificultad con la imagen de alguien queriendo pesar un objeto en una balanza imaginaria (IF 259). Es más, esta persona tampoco podría definir o explicar este término, ya que si lo hiciera, ya podría ser comprensible por otros (IF 258). Luego, este uso se reduciría a una relación causal y ostensiva entre la sensación (digamos, un picor inefable en una zona concreta del cuerpo) y el término (digamos, "bulubü'). Sin embargo, ¿cómo saber cada vez que es la misma sensación, que no es otra distinta?

Quizás podría anotarlo o confiar en su memoria, pero entonces tampoco se descartaría la posibilidad de error, ya que este hablante privado seguiría sin poseer ningún criterio externo para corroborar su error o su acierto, esto es, le

Sharrock en The "Third" Wittgenstein: the post- "Investigations" Works (Aldershot, Ashgate, 2004) y José Medina, a quien me referiré a continuación.

${ }^{8}$ Wittgenstein sólo dice "genio" lo de "poco empático" lo ha introducido la autora del artículo. 
faltaría el uso común y compartido de los términos que, según Wittgenstein, es el que permite corregir errores (IF 258). Es decir, ¿cómo se daría un error en este uso privado, cómo distinguirlo de un acierto, si no hay más criterios para corroborarlo que la propia experiencia de un sujeto aislado que es incomunicable o incomprensible para los demás? (IF 270). El uso de una palabra, de una regla, necesita una justificación que todos entiendan y, si este uso se reduce a un solo hablante, no se puede asegurar que haya corrección (IF 261).

A partir de este argumento de Wittgenstein en oposición al juego de lenguaje privado, intérpretes como José Medina han considerado que las reglas de los juegos se pueden entender como normas sociales y trasladan este argumento a un ámbito social. Pasemos a verlo.

\section{La interpretación política y aplicada de la obra del segundo Wittgenstein}

\section{$2.1 \mathrm{El}$ argumento en oposición al juego de lenguaje social}

A continuación, detallaré una extensión del argumento de Wittgenstein, desarrollada por José Medina quien, tras equiparar juegos de lenguaje y formas de vida, argumenta que, si los seguimientos de reglas no pueden ser privados y completamente subjetivos, entonces, a un nivel social, tampoco pueden ser completamente objetivos ni estar fijados por un grupo cerrado de personas. Este intérprete propone una versión paralela del argumento en oposición al juego de lenguaje privado, el "argumento en oposición al juego de lenguaje social", ${ }^{9}$ aunque reconoce que Wittgenstein nunca desarrolló (al menos de modo explícito) la variante social este argumento y que en la obra tardía de este autor existen ciertos elementos que parecerían favorecer una concepción fija y estable de los procesos de seguimientos de reglas, que da base a interpretaciones quietistas u objetivistas de la obra del segundo Wittgenstein,

\footnotetext{
${ }^{9}$ El desarrollo completo de este argumento de Medina se puede leer en su artículo "Wittgenstein as a Rebel. Dissidence and Contestation in Discursive Practices", International Journal of Philosophical Studies, 18: 1, 2010, pp. 1-29.
} 
como la que proponen, por ejemplo, Kristoff Nyíri o Meredith Williams. ${ }^{10}$

Medina se va a oponer a estas interpretaciones para proponer una concepción crítica de la filosofía, relacionada con la posibilidad de modificar las reglas de los juegos o, incluso, de desobedecerlos. Para ello, distingue dos niveles en los juegos de lenguaje: por un lado, están los consensos o acuerdos de fondo que subyacen y anteceden a los juicios y las prácticas humanas. Se trata de las bases firmes o "roca dura" que no se puede discutir ni debatir y sólo admite explicaciones como: "Así hacemos las cosas en este lugar" (IF 217). Por otro lado, y a diferencia de las interpretaciones quietistas o colectivistas, Medina destaca que estas bases comunes o acuerdos de fondo no implican que haya uniformidad ni, mucho menos, obligatoriedad en los seguimientos de reglas, sino que la comprensión misma de cuál es el contenido de una regla y cómo se pone en práctica en las comunidades humanas ya abre la posibilidad de que esa regla se siga de modo distinto o, incluso, que no se cumpla. Esto es, aunque haya una base común que posibilite el entendimiento entre humanos, esta base no conduce al consenso o uniformidad de opiniones, sino que una regla se puede seguir de modo distinto (IF 74, 87, 213).

Diferencia entonces Medina los acuerdos de base, que se dan en los inicios de un juego de lenguaje en un sentido cronológico, cuando se aprende a seguir una regla (esto es, que para opinar o discrepar alguien haya tenido que aprender, incorporar y aceptar ciertas bases comunes de los juegos de lenguaje) y los procesos cotidianos de seguimientos de reglas que llevan a cabo seres humanos que ya han aprendido a seguir reglas y pueden variar, debatir o discrepar sobre ellas. Si se confunden estas dos dimensiones, continúa Medina, se comete un error paralelo al que cometía el hablante que pretendía mantener un juego de lenguaje privado, exclusivo solo para él (IF 258) y nos alejamos de las prácticas cotidianas del lenguaje y de los procesos de seguimientos de

${ }^{10}$ La interpretación de Kristoff Nyíri se encuentra en su artículo “Wittgenstein’s Later Work in Relation to Conservatism" en McGuiness (ed.), Wittgenstein and his Time. Chicago, University of Chicago Press. Chicago, 1981, pp. 44-68. La de Meredith Williams en Wittgenstein, Mind and Meaning, Nueva York, Routledge, 1999. Si se quiere saber más sobre estas interpretaciones y la crítica de Medina a las mismas se puede leer mi artículo: Gamero Cabrera, "Rules and Bedrocks within a Socio-political realm" (The Philosophical Forum, Vol 47.2., 2016, pp. 131-150) 
normas, donde hay discrepancias, desacuerdos y fricción.

Esto es, siguiendo la recomendación de Wittgenstein de resolver malentendidos en los juegos de lenguaje (IF 90) y llevar los usos del lenguaje de un ámbito metafísico a uno cotidiano (IF 116), Medina localiza y critica dos errores paralelos en la comprensión de los procesos de seguimiento de normas: el subjetivismo (que sitúa la capacidad de agencia en un plano individual y separado del grupo, esto sería el juego de lenguaje privado) y el objetivismo o colectivismo (que sustrae la capacidad de agencia a los individuos y la sitúa a un nivel superior, colectivo o social, limitando la capacidad de acción individual).

Según Medina estas dos comprensiones surgen de un malentendido sobre el funcionamiento de las normas en contextos sociales: en el subjetivismo se da un énfasis excesivo a la acción individual, sin tener en cuenta que los usos del lenguaje y los procesos de seguimiento de reglas son prácticos, públicos y compartidos; en el colectivismo, en cambio, se da un énfasis excesivo a la dimensión social y colectiva de las prácticas humanas, totalizándolas, sin tener en cuenta que son las personas quienes crean las reglas, las siguen (o deciden no seguirlas). En ambos casos, continúa Medina, este exceso de énfasis se puede entender como el mantenimiento de una comprensión ideal, estricta y completamente clara de las reglas que se aparta de los usos cotidianos y pretende reducirlos a un único caso: el individual o el colectivo.

Para desarrollar esta crítica y proponer una concepción pluralista, variable y más realista de los procesos de seguimiento de reglas, Medina propone dos argumentos, inspirados en la argumentación de Wittgenstein en oposición al juego de lenguaje privado, y que paso a exponer:

En primer lugar, para Medina no es posible que un grupo concreto trate de fijar o monopolizar los usos del lenguaje, sin contar con otros usos o interpretaciones (donde también cabrían críticas), ya que en estos casos se habría vaciado de contenido la norma y no sería posible encontrar, corregir o criticar los errores de estos usos. Al igual que el solipsista no podía discernir ni enmendar los errores de su juego de lenguaje privado, según Medina, en el juego de lenguaje social también faltaría una instancia común de corrección y de crítica. El origen de esta instancia de corrección se encuentra, como ya se ha explicado, en la práctica compartida de cada juego del lenguaje y en la 
posibilidad de cuestionar el uso de una regla, que no es unívoca, obligatoria, ni fija, sino que está abierta a cambios y variaciones.

Medina sostiene entonces que cuando no es posible oponerse a las normas establecidas, los juegos de lenguaje dejan de funcionar, porque se ha vaciado su contenido normativo o se ha dado una imposición, tan estricta y distanciada de las prácticas cotidianas, que resulta imposible reconocerla o aplicarla. Éste es el núcleo del argumento en oposición al juego de lenguaje social: si el solipsista cometía el error de creer que los significados pueden ser autónomos y propios, quienes intentan proponer un uso colectivista y objetivista del lenguaje cometen un error paralelo, al entenderlos como completamente heterónomos y separarlos de la agencia humana. No obstante, si se examina más de cerca estas comprensiones, se descubre que están vacías, no son reales, sino consisten en una imagen ontológica de la realidad, esto es, en una proyección de cómo debería ser el lenguaje que se impone desde fuera, con la seguridad y convicción de que "las cosas deben ser así" (IF 114), sin tener en cuenta que se puede pensar lo que no es el caso y que podría ser de otro modo (IF 95).

El segundo argumento de Medina se refiere a la dimensión temporal: con sus intentos de fijar y homogeneizar los usos del lenguaje, ni los subjetivistas ni los objetivistas han tenido en cuenta que las prácticas humanas, las reglas de los juegos no han sido siempre iguales, no son fijas ni unívocas, sino que tienen un origen histórico, una cierta evolución o cambio, sin teleología. Las reglas de los juegos son prácticas continuadas que devienen habituales y necesitan ser reforzadas y reiteradas, constantemente, para que no se pierdan u olviden y, por esto mismo, en su ejercicio, pueden variar. En este sentido, Medina recuerda que para Wittgenstein los juegos de lenguaje son como una ciudad con calles cambiantes (IF 18) o que en todo lenguaje hay "innumerables géneros diferentes de empleo de todo lo que llamamos 'signos', 'palabras', 'oraciones'. Y [que] esta multiplicidad no es algo fijo, dado de una vez por todas, sino que nuevos tipos de lenguaje, nuevos juegos de lenguaje (...) nacen y otros envejecen y se olvidan" (IF 23). Entonces, la principal dificultad de esta comprensión fija e inmóvil de las reglas es que puede llegar a perder de vista, o incluso anular, esta posibilidad de cambio, que no es sólo teórica, sino real, ya que los seres humanos somos distintos y los procesos de seguimiento de reglas son múltiples, diferentes y pueden surgir (de hecho, 
surgen) conflictos, desacuerdos y discrepancias. Entonces, cualquier comprensión fija y obligatoria de las reglas del juego se halla tan distanciada de los usos cotidianos del lenguaje (donde persisten los desacuerdos y los errores), que no resultaría posible saber si se está respetando o no esta norma obligatoria, ya que faltaría, de nuevo, una instancia común de corrección y de crítica (cabría decir, un contraejemplo) para validar este uso lingüístico.

En resumen, si un grupo trata de definir e imponer un uso obligatorio y unívoco del lenguaje o de sus reglas, resultaría imposible saber si en los usos cotidianos se están respetando estos usos o no y, además, la normatividad quedaría bloqueada entre una proyección perfecta (obligatoria pero imposible de cumplir) y esos usos cotidianos que, en comparación con la proyección perfecta, resultan imperfectos o ininteligibles. Como ya mantuvo Wittgenstein (IF 107), cuando los presupuestos de las teorías son demasiado exigentes: "Vamos a parar a un terreno helado donde falta la fricción y así las condiciones son en cierto sentido ideales, pero también por eso mismo no podemos avanzar. Queremos avanzar; por ello necesitamos la fricción. ¡Vuelta a terreno áspero!”.

Intentando regresar a este terreno áspero, Medina insiste en que la multiplicidad y diversidad de las prácticas humanas (o, si lo decimos con Wittgenstein, de las distintas formas de seguir una regla) no pueden desaparecer en nombre de un ideal unívoco e incuestionable (ni autónomo y privado, ni heterónomo y colectivo), sino que siempre se debe tener en cuenta la pluralidad de los significados y las prácticas humanas, así como sus posibles cambios.

Como ya se ha explicado, estos cambios no se pueden hacer de una sola vez, sino que se dan a lo largo del tiempo. Las reglas de los juegos no son necesarias ni fijas, sino habituales y convencionales, necesitan repeticiones y seguimientos comunes para su establecimiento y continuidad, por lo que pueden cambiar. Estos cambios se pueden dar de forma no guiada (por ejemplo, las transformaciones del lenguaje, como la pérdida progresiva del subjuntivo), y también pueden tener una direccionalidad e intención concreta, como cuando un grupo de personas oprimidas protesta y actúa en oposición a la norma que les discrimina y así logra cambiar esa norma. Llevando la argumentación de Wittgenstein a un terreno político, el ejemplo que da Medina para ilustrar este segundo caso es cuando Rosa Parks se negó a dejar su asiento del autobús a una persona blanca y, con su negativa a seguir una norma social que la excluía, inició un movimiento que llevó a la eliminación de las normas 
que discriminaban a la población de color en EEUU. ${ }^{11}$ Esto es, manteniendo su oposición a cualquier intento de homogeneizar o fijar las reglas de los juegos, por sus posibles efectos opresores, Medina reivindica la necesidad de que haya resistencia o fricción epistémica en los seguimientos de reglas. Esto sucede cuando un colectivo (generalmente minoritario u oprimido) denuncia su situación de opresión o de falta de representación, debida a una interpretación muy restringida de una regla, y trata de modificar estas reglas, para que acojan y reconozcan a más personas distintas, sus necesidades y demandas. ${ }^{12}$

\subsection{La reversibilidad de los juegos de lenguaje}

Tras explicar los argumentos en oposición a los juegos de lenguaje privados y sociales, regreso a la consideración, presentada al inicio de estas páginas, sobre la posibilidad de equiparar juegos de lenguaje y formas de vida, y las reglas de los juegos con las normas sociales, ya que el argumento de Medina en oposición al juego de lenguaje social y sus efectos en las vidas humanas son las principales razones a favor de esta equiparación y esta comprensión social de la obra de Wittgenstein. Esto es, la consecuencia principal que Medina deduce de esta reformulación (algo heterodoxa) del argumento de Wittgenstein en oposición al juego de lenguaje privado es que nadie, ningún individuo o grupo, puede fijar un uso del lenguaje e imponerlo a los demás, sino que cualquier significado, si está en uso, puede ser modificado, disputado y criticado por cualquier otro hablante. Afirmando su compromiso con los grupos minoritarios que pueden estar perjudicados por ciertas normas sociales, que se presentan como obligatorias pero que son, en realidad, convencionales y modificables, Medina redefine la argumentación de Wittgenstein para pensar en los casos donde se dan usos ofensivos y denigrantes del lenguaje (por ejemplo, contenidos críticos, sexistas o racistas) y proponer una teoría y una práctica para tratar de eliminar estas conductas ofensivas. Esto es, si un sector concreto de la sociedad (especialmente, un sector privilegiado que posee lo que Medina denomina "autoridad

\footnotetext{
${ }^{11}$ Medina, José: The Epistemology of Resistance, Nueva York, Oxford University Press, 2013, p. 75 .

12 Medina, The Epistemology of Resistance, pp. 78 y ss.
} 
epistémica"13) comienza a dar un uso ofensivo o insultante de un término para criticar y menospreciar a ciertas personas o grupos minoritarios, estas mismas personas o grupos insultados ya están legitimadas para oponerse a ese uso del lenguaje, criticarlo y modificarlo, en virtud del argumento en oposición al juego de lenguaje social ya explicado. Lejos de existir una concepción única y obligatoria de las reglas, según esta interpretación de Medina, las normas sociales son reversibles, se pueden criticar y cambiar.

Esta propuesta coincide con las de Peg O'Connor y Miranda Fricker quienes también parten de la obra del segundo Wittgenstein para desarrollar propuestas de epistemología crítica y admiten la equiparación entre juegos de lenguaje y formas de vida para dar una comprensión pluralista y cambiante de las sociedades humanas. Por ejemplo, para Fricker, lo que llamamos "verdadero" y "falso" no son contenidos fijos o absolutos, ya que dependen de ciertos juicios previos y de la aceptación de ciertas formas de vida y conductas, que son variables. ${ }^{14}$ Esto es, los hechos sociales, lo que llamamos "realidad", se asientan en unos juicios previos sobre qué es lo bueno, qué valoramos más o incluso qué sujetos son más fiables y convincentes. Estos distintos juicios ocasionan que haya distintas interpretaciones posibles de un mismo hecho (por ejemplo un comentario gracioso de un hombre hacia una mujer puede ser interpretado como una broma o como un insulto).

Este pluralismo de interpretaciones también conlleva que los contenidos emitidos no son todos iguales ni neutros, sino que presentan intereses y, dependiendo de quién hable, estas valoraciones o interpretaciones van a tener mayor o menor aceptación. Esto es lo que la autora denomina "privilegio epistémico", que contrasta con la situación de personas que reciben estas interpretaciones "desde fuera" y no tienen tanto privilegio o reconocimiento para responder o defenderse, al sufrir lo que Fricker denomina "opresión epistémica". 15

En el ejemplo anterior, si el hombre que hace el comentario gracioso

\footnotetext{
${ }^{13}$ Medina, The Epistemology of Resistance, p. 59.

${ }^{14}$ Fricker, Miranda: "Epistemic Oppression and Epistemic Privilege", en Canadian Journal of Philosophy, Vol. 29, Issue 1-2, 1999, p. 206. Está citando el aforismo 241 de las Investigaciones.

${ }^{15}$ Fricker, Miranda: Epistemic Injustice, Oxford, Oxford University Press, 2009, pp. 20 y
} 
tiene mucha autoridad epistémica, cualquier respuesta que dé la mujer tiene una mayor posibilidad de ser entendida como una defensa "pasiva agresiva", histérica o inmotivada y esta comprensión debilita, y prácticamente impide, cualquier argumentación, crítica o defensa que pueda dar esta mujer. Por el contrario, si ella tuviera algún privilegio epistémico o fuerza para responder, sus protestas podrían ser recibidas como una crítica feminista legitimada, que dejaría en una mala posición al varón. Entonces, según Fricker, aunque resulta necesaria una cierta regularidad en las prácticas sociales y consensos prácticos en los usos del lenguaje para que haya entendimientos, esto no significa que tenga que haber unanimidad o univocidad en los significados y las interpretaciones que se den a los hechos, sino que tienen que estar abiertos a cuestionamientos, críticas y protestas. Si se entiende, por el contrario que solo hay un punto de vista o interpretación posible donde no cabe discusión, se corre el riesgo de anular el pluralismo y silenciar las voces de personas que discrepan o tienen una opinión diferente a la hegemónica. En ese caso, nos encontraríamos ante situaciones de opresión epistémica en las que las quejas o reivindicaciones de ciertos colectivos no pueden ser expresadas o, incluso si se expresan, pueden no ser comprendidas o ser recibidas con críticas y escepticismo, que les quitan peso y anulan. Fricker propone entonces ser más sensibles a otras interpretaciones y estar atentos a las opiniones y posturas no mayoritarias, para que haya una mayor representación y reconocimiento de las diferencias, en vez de una única voz hegemónica que tiende a silenciar al resto. ${ }^{16}$

Por su parte, la filósofa Peg O'Connor también traslada las críticas de Wittgenstein al idealismo lingüístico (IF 115 passim) a un terreno social, para criticar cualquier comprensión inmovilista y cerrada del lenguaje y de sus prácticas, que no permita el pluralismo humano y que tienda a imponer una forma de vida sobre otras. ${ }^{17}$ Como ya se ha mencionado, en su obra tardía Wittgenstein mantuvo que los lenguajes eran cambiantes, cabría incluso decir que estaban vivos o que consistían en formas de vida, ya que hay “innumerables géneros diferentes de empleo de todo lo que llamamos 'signos',

ss.

${ }^{16}$ Fricker, Miranda: "Epistemic Oppression and Epistemic Privilege", pp. 206-208.

17 O’Connor, Peg: Oppression and Responsibility, Pennsylvania, Pennsylvania State University, 2002, p. 136. 
'palabras', 'oraciones'. Y esta multiplicidad no es algo fijo, dado de una vez por todas, sino que nuevos tipos de lenguaje, nuevos juegos de lenguaje (...) nacen y otros envejecen y se olvidan" (IF 23).

A partir de esta cita, O'Connor argumenta que los lenguajes y las formas de vida que están relacionadas con ellos no están fijas y dadas, de una vez por todas, sino que pueden cambiar y siempre están sujetas a críticas y renovaciones. Esto es, del mismo modo que no se puede mantener que haya un único ideal de precisión y exactitud al que debamos aspirar (IF 88), tampoco cabe decir que haya una única forma de vida, mejor que todas, sino que existen diferentes concepciones de lo bueno, que pueden cambiar y, en ocasiones, hasta entrar en conflicto. ${ }^{18}$

Este paisaje de múltiples formas de vida cambiantes y en conflicto potencial no se puede anular en nombre de una imagen perfecta, inmutable y cerrada, ya que se estaría cayendo en lo que Wittgenstein diagnosticó como el dogmatismo en el que tan fácilmente se cae al filosofar, esto es, imponer un prejuicio como la imagen ideal a la que la realidad debe corresponder (IF 131). Por el contrario, O'Connor propone apartarse del ideal para admitir el pluralismo humano, los cambios en los juegos de lenguaje y las posibles críticas que se den entre ellos. ${ }^{19}$ En nombre de este pluralismo y estas diferencias, la autora reivindica la necesidad de hacer cambios en los juegos de lenguaje y en las prácticas humanas, con creatividad e incluso provocación. Y asimismo encuentra elementos en la obra de Wittgenstein que fortalecen esta comprensión cambiante y crítica de los juegos de lenguaje; por ejemplo, cita el aforismo 63 de Sobre la Certeza: "Si imaginamos los hechos distintos a como son, ciertos juegos de lenguaje pierden importancia mientras que otros se convierten en importantes. Así se transforma, poco a poco, el uso de los términos en un lenguaje"

También cita el siguiente pasaje del Big Typescript para argumentar que los cambios que se dan en los juegos de lenguaje suelen estar promovidos por personas rebeldes e insatisfechas que no se sienten cómodos con sus

18 O'Connor, Peg: Oppression and Responsibility, pp. 11-12.

19 O'Connor, Peg: Oppression and Responsibility, pp. 136-137. 
circunstancias o su contexto.

Algunas personas están profundamente inmersas en confusiones gramaticales, es decir, filosóficas. Para liberarlas, hay que expulsarlas al exterior de la ingente cantidad de relaciones y vínculos en las que están atrapadas. Por así decirlo, se debería reagrupar todo su lenguaje. Pero este lenguaje surgió de esta manera porque estas personas tenían -y tienen- la tendencia a pensar así. Por lo tanto, esta expulsión sólo funciona con quienes viven en un estado instintivo de rebelión/ / de descontento con el lenguaje; no con quienes viven siguiendo todos los instintos del rebaño que creó este lenguaje como su forma adecuada de expresión". ${ }^{20}$

A partir de estos pasajes, O'Connor mantiene que los usos del lenguaje, y las formas de vida que se relacionan con ellos, no pueden ser entendidos como cerrados, fijos u obligatorios, ya que entonces pueden generar opresiones y violencias a quienes no estén representados por esos usos. Como alternativa, propone posibles cambios, con resistencia, crítica e imaginación, para que se amplíen las posibilidades vitales de distintos grupos humanos. Para ilustrar esta propuesta se refiere a la expresión "violación conyugal" [marital rape] que, según la concepción tradicional del matrimonio, parecía no tener sentido, podría entenderse incluso como un oxímoron. Sin embargo, nos encontramos ante una forma de violencia real que no puede ser reconocida en un marco concreto y opresor (el de la concepción tradicional del matrimonio). Esta norma social, esta imposibilidad de nombrar, creaba mucho sufrimiento a las mujeres que sufrían tal forma de violencia; pero, además, trasciende al lenguaje ya que si algo no se puede nombrar (o el nombre se entiende como un uso incorrecto) tampoco se puede debatir, sacar a la luz, denunciar o juzgar. En este caso, continúa O'Connor, fue necesario que distintas mujeres que sufrían esta forma de violencia compartieran su malestar, le pusieran nombre y lo denunciaran, cambiando así su juego de lenguaje y su forma de vida. Esto es, no basta con reconocer que existe esta forma de violencia, ni de acuñar un nuevo término; sino que este reconocimiento y este acto de nombrar van unidos a una actitud crítica y a unas prácticas de denuncia, donde se proyecta una situación mejor

20 Wittgenstein, Ludwig: Big Typescript, 90, Item 213, Londres, Blackwell, 2005, p. 423 (traducción al castellano y cursivas de la autora del artículo, barras laterales de Wittgenstein). 
para estas mujeres. ${ }^{21}$

Citando el pasaje de las Investigaciones ya aludido: "Imaginar un juego de lenguaje significa imaginar una forma de vida" (IF 19), esta autora mantiene que las reglas, los usos y los significados de los juegos de lenguaje no se pueden entender como fijos y cerrados, ya que entonces se corre el riesgo de que ciertas personas no sean reconocidas como hablantes legitimados o garantes de derechos y, por el contrario, puedan ser dañadas. Para evitar esta posibilidad, O'Connor insiste en la plasticidad de los usos del lenguaje y en la fuerza de la imaginación que lleva a los seres humanos (especialmente a quienes están en una situación de injusticia o sufrimiento) a cambiar las reglas del juego y reivindicar otros usos del lenguaje, otros significados y formas de vida donde sí sean reconocidos y puedan articular sus demandas, quejas y reivindicaciones. ${ }^{22}$

En conclusión, la clave del argumento en oposición al juego de lenguaje social es que, desde el momento en que un grupo de personas es insultado y atacado por ciertas prácticas o usos del lenguaje, este grupo ya está reconocido e interpelado por estos mismos usos, por lo que, en principio, además de recibirlos, también pueden subvertirlos y criticarlos. Los usos del lenguaje tienen que ser reversibles y modificables, en caso contrario, nos encontraríamos ante unos usos unilaterales, obligatorios y sin alternativas, que no dejarían representación o expresión posible a nadie más, por lo que carecerían de validez, estarían vacíos de contenidos o tan cerrados que no podrían ser comprensibles, como le sucedía a quien pretendía crear un juego de lenguaje privado.

Si se acepta esta igualación entre juegos de lenguaje y formas de vida y esta aplicación de los argumentos de Wittgenstein a circunstancias y conflictos sociales como los descritos, se abre una vía teórica y práctica con resultados prometedores para comprender, describir y tratar de evitar ciertos usos del lenguaje, ligados a prácticas opresivas u ofensivas. Esto es, en virtud del argumento en oposición al juego de lenguaje social, los procesos de seguimientos de reglas no son fijos ni obligatorios, sino que están abiertos a interpretación y discusión. Asimismo, cualquier persona interpelada por un uso

${ }^{21}$ O'Connor, Peg: Oppression and Responsibility, pp. 37-38.

22 O'Connor, Peg: Oppression and Responsibility, p. 97 
del lenguaje o una práctica ya participa en ese mismo juego, por lo que comienza a tener poder para responder a estos usos y prácticas y subvertirlos. Por supuesto, este proceso no es fácil ni inmediato ya que, generalmente, quienes llevan a cabo estos usos ofensivos tienen más autoridad epistémica y reciben más reconocimiento que quienes son atacados y denostados. No obstante, ser conscientes de que los usos del lenguaje y las prácticas sociales pueden ser ofensivas y que no todo el mundo tiene la misma posibilidad o fuerza para transformarlas y modificarlas, ya es un avance para reconocer este tipo de prácticas y tratar de evitarlas.

\section{Juegos de lenguaje sociales de grupos oprimidos}

El último paso para cerrar esta argumentación y ver los límites de esta comprensión aplicada de la obra de Wittgenstein sería preguntar qué sucedería en el caso de que un grupo, que generalmente es oprimido o minoritario, decidiera crear o monopolizar un uso del lenguaje, una norma o una práctica, al considerar que nadie más que ellos están legitimados para usar ese término, seguir esa norma o llevar a cabo esta práctica. ¿Nos encontraríamos ante otro caso de juego de lenguaje social que se cierra en sí mismo y se vacía de normatividad o se trata de un supuesto distinto?

Para responder a esta pregunta y acabar de detallar el argumento en oposición al juego de lenguaje social, presentaré dos casos y los analizaré bajo la óptica del argumento presentado.

\subsection{Dos casos}

\section{a) Las denominaciones de los huicholes}

Cabe encontrar un posible caso de uso privativo y exclusivo del lenguaje en las denominaciones y autodenominaciones de ciertas comunidades originarias en México, que usan un término para referirse a sí mismos y otro distinto para que los nombren personas que no pertenecen a su comunidad. Así hacen los huicholes, uno de los cuatro grupos indígenas de la región del Gran Nayar, en el centro-oeste de México, que viven en los estados de Jalisco, 
Nayarit, Durango y Zacatecas. ${ }^{23}$

La mayor parte de los miembros de esta comunidad poseen lo que García Canclini ${ }^{24}$ ha llamado una cultura híbrida, esto es, combinan las costumbres y ritos de su forma tradicional de vida con elementos más hispanos y occidentales. Por ejemplo, celebran una Semana Santa sincrética, donde unen sus ritos tradicionales con las costumbres y celebraciones católicas, y casi todos ellos, sobre todo los más jóvenes, son bilingües de español y wixaritari waninki, una lengua prehispánica de la familia yuto-azteca, que en castellano se conoce como "huichol". 25

Este término, "huichol", es problemático y va a ser el objeto de análisis de este caso: se trata del gentilicio que se usa en castellano para designar a una persona o característica de esta comunidad, referida a su etnia, su cultura, su forma de vida o su lengua. Sin embargo, los miembros de este grupo no usan este adjetivo sino "wixarika" (pronunciado "wisalika" o "wicharika"), que es el término de la lengua wixaritari que los designa, su propio gentilicio, y no permiten a nadie externo que use este término. El primer motivo que aducen para estos dos usos diferenciados y este veto es que los hispanohablantes no sabemos pronunciar el término "wixarika" y que deformamos el nombre con el que ellos se identifican. En este sentido, y según distintas fuentes ${ }^{26}$, el origen de la palabra "huichol" es la castellanización de "wixarica", debido a que los primeros conquistadores no podían pronunciar este término y acabaron modificándolo y adaptándolo a una expresión más fácil de decir, que es

\footnotetext{
${ }^{23}$ Neurath, Johannes: Huicholes. Pueblos indígenas del México contemporáneo, México DF, Editorial de la CDI (Comisión Nacional para el Desarrollo de los Pueblos Indígenas), 2003, p. 6. Además de a las obras citadas, parte del contenido de esta sección se lo debo a Tutupika Carrillo, Astrid Velázquez y Edisa Altamirano, quienes me explicaron (no sin ciertas reticencias) algunos elementos de la cultura huichol.

${ }^{24}$ García Canclini, Néstor: Culturas Hibridas, México, Grijalbo, 1990.

${ }^{25}$ Iturrioz Leza, José Luis y de la Cruz, Julio: "El proceso de traducción entre español y huichol", Estudios de Traducción. Vol. 2, 2012, p. 134

${ }^{26}$ Iturrioz, José Luis: "Etimología de las palabras wisalika y huichol”, en Niuki. Revista de divulgación académica y cultural, Universidad de Guadalajara, No 2, mayo-agosto 2007, pp. 19 y ss. Véase también Neurath, Johannes: Huicholes, y Negrín, Juan: Acercamiento histórico y subjetivo al huichol, Guadalajara, Publicaciones de la Universidad de Guadalajara, 1985.
} 
incorrecta en la lengua wixaritari. Por su parte, aunque se barajan varias posibilidades sobre el origen del término "wixarika" ${ }^{27}$, en realidad, se desconoce su verdadero significado y los miembros de esta comunidad son bastante reacios a explicarlo a alguien externo ${ }^{28}$. Tampoco son proclives a explicar el significado de sus ritos y costumbres ya que, para ellos, este uso restringido y esta negativa a explicarse es una manera de preservar su forma de vida y de distanciarse de los hispanohablantes quienes, desde el momento de la conquista, doblegaron a los huicholes, no sólo con un dominio lingüístico (esto es, la imposición del castellano y la prohibición de usar su idioma nativo), sino también territorial: al apropiarse de sus tierras y esclavizar a sus antepasados para que trabajaran en los campos que antes les pertenecían. Además, también se dio un dominio ideológico, sobre todo por parte de sacerdotes católicos que prohibieron los costumbres y ritos tradicionales huicholes y mandaron destruir los centros de ceremonias tradicionales (calibueyes), para edificar iglesias. ${ }^{29}$

En 1857 hubo un levantamiento huichol en oposición a este dominio hispánico y, desde entonces, lograron la propiedad comunal de sus tierras y una cierta independencia, que siguen defendiendo hasta el presente con estos usos diferenciales de los términos y renuencias a dar información sobre sus costumbres y formas de vida Entonces, pese a convivir, en hibridez con los mexicanos no indígenas, los huicholes son una de las comunidades más resistentes a la dominación hispánica y una de las muestras de esta resistencia es la monopolización del término que usan para referirse a sí mismos.

\section{b) Las transformaciones feministas y transfeministas del lenguaje}

Otro caso donde un grupo que ha recibido opresión crea o modifica un uso del lenguaje es la nueva forma de plural genérico (por ejemplo, con '@)' o

\footnotetext{
${ }^{27}$ Para Lumholtz (1900), el primer antropólogo que escribió sobre los huicholes, el término "wixarica" significa "doctor", "sabio", "curandero" o "adivino". Posteriormente, también se mantiene que significa "agricultor" o "ser humano". Citado a partir de Negrín, Juan: Acercamiento bistórico y subjetivo al buichol, pp. 10 y ss.

${ }^{28}$ Sánchez Domínguez-Guilarte, María de la Concepción: "Los Wixaritari a través de la Antropologia, la Historia y la Literatura", en Fronteiras: Revista de História, Vol. 18, N ${ }^{\circ}$ 32, 2016, pp. 56 y ss.

${ }^{29}$ Neurath, Johannes: Huicholes, p. 8.
} 
con ' $\mathrm{x}$ ') que proponen algunas feministas para designar a un grupo de personas integrado por hombres y por mujeres y que se diferenciaría del plural genérico masculino, que pasaría a designar sólo a un grupo de varones. Este uso feminista se dirige a mostrar y denunciar un síntoma (lingüístico) de un malestar (social). Según la Real Academia de la Lengua, el plural masculino es genérico y neutro, incluye igualmente a hombres y mujeres; el plural femenino, por su parte, es particular y marcado, sólo se refiere a un grupo femenino. ${ }^{30}$

La crítica de las feministas a esta comprensión es que el lenguaje no es un transmisor neutro y sin valores, sino que mediante él se expresan, reconstruyen y reproducen las relaciones de poder que tradicionalmente han fomentado el dominio de los varones sobre las mujeres ${ }^{31}$. Por ejemplo, según Pérez Orozco, si alguien no se siente cómodo en un mundo social, puede intentar cambiarlo, pero para ello, necesita poder pensar, comprender y expresar su malestar. $\mathrm{Y}$ esto requiere poder conocer y nombrar las cosas; crear categorías y relatos que permitan una ruptura con la hegemonía discursiva que impone un único mundo posible, ya que "hay mundos que no se pueden nombrar desde la norma que se nos ofrece". ${ }^{32}$

Por lo argumentado anteriormente, ya debe quedar claro que esta crítica feminista no es sólo lingüística, sino también social, ya que el lenguaje no se da de modo separado del tejido social y de la forma de comprender y vivir la realidad. Por ejemplo, una de las problemáticas que no se pueden expresar con el lenguaje hegemónico (masculino genérico) disponible es la situación actual donde parece que las mujeres participan como iguales con los varones en el ámbito público y en el mundo laboral, pero no reciben un mismo trato, ni un mismo salario, existiendo por ejemplo techos de cristal o una mayor carga de trabajo para ellas.

Desde el feminismo se problematiza esta inclusión acrítica de las mujeres en un ámbito genérico masculino (pretendidamente universal y neutro, pero

\footnotetext{
${ }^{30}$ Véase el artículo de Ignacio del Bosque "Sexismo lingüístico y visibilidad de la mujer" (El País, 4 de marzo de 2012).

${ }^{31}$ Repes, Laura y Pérez-Barahona, Beatriz: "Norma Lingüística e Ideología” (Periódico Diagonal, 11 de julio de 2013).

32 Pérez Orozco, Amaia: Subversión Feminista de la Economía, Madrid, Traficantes de Sueños, 2014, p. 29 y nota al pie 10 (cursivas de la autora del libro).
} 
históricamente masculino) porque supone la invisibilización de las mujeres y sus problemáticas concretas y no permite la transformación de estos ámbitos, eminentemente masculinos. Esta inclusión acrítica se corresponde con lo que Pérez Orozco ha denominado el modelo "añada mujeres y remueva", 33 que entiende la igualdad entre géneros como igualdad neutral e indiferente y que pretende solucionar las dificultades de las mujeres con su inclusión en ámbitos anteriormente monopolizados por varones (como los puestos de directivos, de liderazgo político o los altos cargos en instituciones púbicas), pero nunca se cuestiona el funcionamiento de estos ámbitos o su estructura. Con esta solución neutra, continúa Pérez Orozco, se invisibilizan problemas y dificultades de las mujeres y de otras personas que no se identifican con el modelo hegemónico masculino, ya que se fomenta y se celebra la inclusión de estas personas en el mundo laboral o en la esfera pública exactamente igual (en un sentido neutro) que el varón, pero no se tratan problemáticas específicas como las mencionadas. Es decir, mientras estas mujeres participan como varones en el mundo laboral, ¿'son ellas mismas las que trabajan en una doble jornada, en el trabajo y en el hogar? ¿Son otras mujeres, de clase más baja y más vulnerables, las que realizan estas tareas, estableciéndose entonces una nueva diferencia entre mujeres-neutrales que trabajan como varones y mujeresmujeres que siguen haciendo las tareas del hogar?

Para visibilizar esta falsa neutralidad que invisibiliza problemáticas femeninas (y también de personas transexuales), y como un acto de provocación, algunos colectivos feministas han empezado a usar términos como "nosotr@s" o "nosotrxs" para designar a un grupo de personas compuesto por hombres y mujeres. Por supuesto, no proponen sólo una transformación del lenguaje sino de las estructuras sociales que van parejas con el lenguaje. De este modo, animan a desobedecer la norma lingüística para ampliar el marco de pensamiento, de expresión de crítica y de acción.

También se dan expresiones más radicales de esta transformación de los usos del lenguaje, movidas por reivindicaciones feministas, como el uso del plural genérico femenino ("nosotras") para referir a un grupo compuesto por varones y mujeres, muy común en movimientos sociales post $15 \mathrm{M}$ en España y que ha llegado a calar incluso en la forma de expresión de algunos políticos

${ }^{33}$ Pérez Orozco, Amaia: Subversión Feminista de la Economia, p. 32 
de partidos como Podemos. ${ }^{34}$ Por último, cabe encontrar una manifestación aún más subversiva de esta transformación del lenguaje, en algunos colectivos transfeministas quienes, para desmontar el dimorfismo lingüístico y social que divide la realidad en varones y mujeres (o en usos masculinos y femeninos del lenguaje) y que invisibiliza así a las personas que no se identifican con ninguno de los dos géneros normativos, llevan a cabo una desarticulación de la gramática y de los géneros lingüísticos. Proponen, por ejemplo, no respetar los géneros gramaticales, la forma habitual de puntuación, ni el uso de las mayúsculas y minúsculas o mezclar palabras de distintos idiomas, con la intención de convertir el lenguaje en "señal de un devenir minoritario posible" y plantear "la necesidad de relacionarse con el texto como una jungla de contextos y lenguajes". 35

Encontramos un ejemplo de esta propuesta en el colectivo mery sut, compuesto por distintas personas, de distintas nacionalidades y orientaciones sexuales, que cuestionan todos los binarismos que categorizan y limitan la comprensión de la realidad y de los cuerpos, y transforman el lenguaje y las prácticas sociales para abrir una pluralidad de interpretaciones y acciones diferentes y cambiantes. Transcribo a continuación, y sin modificar nada, una muestra de su manifiesto para ilustrar cuál es la propuesta de transformación del lenguaje que hace este colectivo:

somos vidas en relación entre ellas y también en convivencia con otrxs. no se trata de un grupo de personas compact sino de distintas energías que partagent puntos de encuentro y, tal vez, direcciones comunes, imaginarias y reales. cuando coincidimos y nos empeñamos juntas es porque imponemos una privlačnost necesaria entre nuestro imaginario y la realidad. estas $r$ /esistencias toman y cambian de forma en la rabia, en el compartir de micropoliticas everyday, de ejercicios de autocrítica, personales y comunes, de autoempoderamientos, de forma de autoayuda mutua, de mreža que utiliza internet como medio de comunicación, pero, sobre todo, somos un sólido entramado de amistades y de relations de amor. con estas intenciones

\footnotetext{
${ }^{34}$ Un ejemplo sería el video donde Pablo Iglesias se refiere a sí mismo como "una treintañera, trabajadora y explotada":

35 mery sut, "pistas de lectura" del manifiesto "prácticas de atravesamiento: (over)flow" en Solá (ed.), Transfeminismos, Fricciones, Epistemes y Flujos, Tafalla Nafarroa, Txalaparta, 2013, pp. 141 ss. y nota 2
} 
y en confianza hemos podido enfrentarnos a una larga serie de experiencias transnationales, sexuales, translinguistics. ${ }^{36}$

\subsection{Análisis de los casos}

$\mathrm{Si}$ analizamos estos dos ejemplos bajo el prisma del argumento en oposición al juego de lenguaje social, parece que algo falla: ¿no estaríamos ante nuevos casos de monopolización y usos unilaterales de un juego de lenguaje que sólo pueden ser alterados, apropiados o modificados por sus hablantes?, ¿No se están cerrando estos grupos al pluralismo y la plasticidad de los juegos de lenguaje y monopolizando un uso, entendiendo que es exclusivo sólo para ellos (o ellas)? ¿Se trata, en definitiva, de nuevos ejemplos de juegos de lenguaje sociales, pasibles de ser criticados con argumentos como los de Medina?

Esta objeción es posible. Sin embargo, no hay que olvidar que uno de los motivos que llevaba a José Medina, Peg O'Connor o Miranda Fricker a hacer una interpretación social y aplicada de la obra de Wittgenstein era la constatación de que no todos los participantes de los juegos de lenguaje son iguales y tienen la misma capacidad de expresión y autoridad, sino que, por el contrario, se dan relaciones desiguales de poder entre ellos y unos poseen más autoridad epistémica que otros.

A diferencia de modelos más ideales o neutrales de las sociedades humanas, como por ejemplo el de Habermas, donde todos los seres humanos se consideran iguales, al ser entendidos como hablantes y participantes de un diálogo donde todos parecen tener el mismo derecho a expresión y a réplica (o, al menos, deberían tenerlo), Medina, Fricker y O'Connor destacan, como ya hemos visto, que existen seres humanos y colectivos que están subrepresentados o tienen menos derecho a expresarse que otros y por ello existe la posibilidad de que sean denigrados o infravalorados por algunos usos hegemónicos del lenguaje. Estos autores proponen esta interpretación de la obra de Wittgenstein, por tanto, para fomentar la expresión y la defensa de estas personas o grupos oprimidos ${ }^{37}$.

Los dos casos analizados se pueden entender como ejemplos de estas

\footnotetext{
${ }^{36}$ mery sut, "prácticas de atravesamiento: (over)flow", p. 146.

37 Para facilitar la comprensión de los argumentos me voy a referir, de modo general, a
} 
formas críticas de usar el lenguaje y de cambiar las prácticas humanas para lograr una mayor representación o visibilidad de sus problemáticas y, además, no supondrían excepciones o vulneraciones al argumento en oposición al juego de lenguaje social, sino que también lo confirmarían. Paso a explicarlo:

En el caso huichol, hay que tener en cuenta la dominación lingüística, territorial e ideológica a la que esta comunidad estuvo sometida por parte de los hispanohablantes. Esta situación de opresión se da incluso en el presente, ya que pertenecer a la comunidad huichol no está bien visto en algunos sectores mexicanos. Esto es, parte de la población mexicana no indígena sigue considerando a los huicholes como personas inferiores, ignorantes o pobres y todavía se dan conductas y actitudes racistas hacia los miembros de esta comunidad. Por ejemplo, el mismo término "huichol" se usa en ocasiones de modo despectivo, como un insulto racial (equiparable a "indio") dirigido a denigrar no sólo a los miembros de esta etnia, sino a cualquier persona que parezca indígena o pobre. Es decir, llamar a alguien "huichol" (con independencia de que pertenezca o no a este grupo) es un insulto racial, referido a la apariencia indígena y de pobreza.

Nos encontramos entonces ante un caso de opresión epistémica de un grupo (privilegiado y hegemónico) sobre otro, donde se da, además, un error categorial, propio de lo que Medina denomina "ignorancia epistémica". ${ }^{38}$ Esto es, a quien usa el término "huichol" como insulto no parece importarle mucho la especificidad de este término (es decir, que antropológicamente sólo se refiera a una comunidad concreta y no al conjunto de "lo indio" o "lo indio pobre") y transforma una denominación antropológica en un insulto, lo que también supone un acto de opresión epistémica de un grupo privilegiado sobre

dos grupos: los opresores y los oprimidos. Esta es una simplificación muy basta que no refleja de modo adecuado las complejas situaciones y redes de poder que se dan en la sociedad, donde hay distintos niveles de opresión y una misma persona, dependiendo del momento, puede ocupar la posición de opresor y oprimido. Voy a dar una representación esquemática y dual donde sólo parece haber dos grupos, pues, pero reconozco que esta representación no se adecúa a la realidad social donde todo es mucho más complejo.

${ }^{38}$ Medina, Epistemology of Resistance, pp. 30 y ss. 
otro.

Como respuesta a este uso denigrante e inadecuado del término, la población huichol responde con lo que Medina llama un gesto de resistencia epistémica, ${ }^{39}$ esto es, se rebela, critica y protesta ante un uso que les ofende y que no los representa y reivindican, como alternativa, un uso propio de otro término, wixarica, del que se sienten orgullosos y que es difícil de pronunciar por los castellanohablantes. La diferenciación entre "huichol" y "wixarica" y la reivindicación del segundo es un gesto de empoderamiento de este grupo. Por supuesto, no se trata sólo de un gesto lingüístico, sino también social y político, ya que va a acompañado de la exigencia de respeto a los huicholes, sus tradiciones y costumbres, de peticiones de más fondos estatales para la conservación de sus áreas, de espacios donde poder vender sus productos (sobre todo maíz y artesanía) a precios justos y para lograr una mayor alfabetización y acceso a la educación superior de los huicholes.

En el segundo caso, también se ha dado, histórica y tradicionalmente, una opresión de un sector de la población (el masculino) sobre otro (el femenino), que se ha reproducido tanto en la diferenciación entre espacios públicos y privados, en la distribución de trabajos y tareas, como en el lenguaje, donde lo neutro ha pasado a ser lo masculino y lo femenino ha quedado relegado a un uso particular. Como respuesta a esta dominación, lingüística y social, distintos grupos feministas han levantado una voz crítica y reivindicado un nuevo uso del lenguaje donde no se oculten las problemáticas destacadas. Se trata, asimismo, de un gesto de provocación para visibilizar las dificultades de un sector de la población, tradicionalmente oprimido, y para comenzar a pensar y actuar diferente. Esto es, de nada serviría un uso inclusivo y feminista del lenguaje si no estuviera acompañado de prácticas que reivindicaran una mejor situación para las mujeres. Esta transformación del lenguaje se puede entender entonces como otro gesto de provocación y de resistencia epistémica, que no funciona sólo sino acompañado de demandas, como sueldos iguales para hombres y mujeres, horarios laborales compatibles con la maternidad, prohibición de despidos por embarazo o cuotas para que más mujeres lleguen

${ }^{39}$ Medina, José: Epistemology of Resistance, pp. 48 y ss. 
a puestos de representación.

\subsection{Una vuelta de tuerca al argumento en oposición al juego de lenguaje social}

Para cerrar esta argumentación, quisiera explicar por qué no entiendo que estas reivindicaciones sean ejemplos de juegos de lenguaje sociales ya que, en los casos analizados, los dos grupos que modifican un uso del lenguaje para sus propios fines y reivindicaciones ya están insertos en un ámbito social o juego de lenguaje. Esto es, forman parte de una sociedad (aunque reciban opresiones epistémicas o no estén completamente representados) y conocen las reglas de ese juego, por lo que pueden subvertirlas o modificarlas. Por el contrario, si estos grupos estuvieran completamente fuera del juego de lenguaje o de esa sociedad y no tuvieran representación alguna, sus demandas, críticas, ejercicios de provocación no podrían ser articuladas ni comprendidas en ese juego de lenguaje. Por ejemplo, la diferenciación entre "huichol" y "wixarica" no podría ser articulada de modo crítico por una anciana, miembro de la comunidad huichol, que vive en una zona rural, es analfabeta y sólo habla la lengua wixaritari. Por supuesto, esto no quiere decir que esta anciana no esté oprimida, sino que no podría expresar su opresión a través de la diferenciación entre estos dos términos, ni reivindicar, en castellano, un uso nuevo del lenguaje que sea crítico y subversivo, como hacen los miembros más jóvenes de la comunidad quienes han accedido al sistema educativo mexicano y hablan wixaritari y castellano. Asimismo, si las mujeres no hubieran empezado a acceder al sistema educativo, al mundo laboral y a conocer sus derechos, tampoco podrían reivindicar nuevos usos del lenguaje y nuevas prácticas para mejorar su situación. Esto es, ser competentes en un lenguaje y tener algún papel o representación dentro de la sociedad donde se está oprimido se convierten en condiciones necesarias para transformar las normas opresoras. En los casos analizados, los grupos que pretenden transformar el lenguaje y las prácticas que los oprimen ya forman parte de la sociedad a la que se oponen y critican. Una crítica completamente exterior no podría ser articulada ni tener sentido para ese juego de lenguaje.

En segundo lugar, también resulta necesario que el grupo opresor supere 
lo que Medina llama "ignorancia epistémica", ${ }^{40}$ esto es, que sea consciente de la dominación o violencia que estaban llevando a cabo con sus usos del lenguaje y sus prácticas y que acepten (o incluso, continúen) las prácticas alternativas propuestas por los grupos oprimidos. Esta sería la principal razón por la que las transformaciones del lenguaje analizadas en el apartado anterior no son muestras de juegos de lenguaje sociales.

Retomando el argumento en oposición al juego de lenguaje social, cabe destacar que los subversivos del lenguaje no se pueden dar solo dentro del grupo oprimido y crítico (los huicholes o las feministas), sino que necesitan la aquiescencia de otros grupos (sobre todo de quienes detentan la autoridad epistémica) para que estos usos sean aceptados y continuados, y se eliminen así, progresivamente, las prácticas opresoras. Por ejemplo, si los hispanohablantes no reconocen las diferencias entre "huichol" y "wixarika", ni aceptan que haya usos distintos de estos términos, uno de los cuales les está vedado, esta propuesta crítica difícilmente prosperaría. También resulta necesario que la población mexicana no indígena deje de emplear el término "huichol" con connotaciones racistas y que haya una sensibilización general sobre la discriminación y opresión que ha recibido este grupo. Si la población no indígena que tiene privilegios epistémicos no acepta y respeta el uso diferencial y no cambia su actitud despectiva hacia los huicholes, la reivindicación de esta comunidad no tendría mucha repercusión y su propuesta de modificación del juego de lenguaje sí podría entenderse como un caso de juego de lenguaje social, que se cierra en sí mismo, sólo resulta válido para ellos y no prospera.

En caso de la reivindicación feminista del plural inclusivo sucede algo similar, ya que el grupo tradicionalmente opresor, los varones, también ha de aceptar, o incluso continuar, este nuevo uso para que prospere; lo que no deja de ser una muestra de que, incluso en las sociedades actuales, los hombres parecen seguir teniendo una mayor autoridad epistémica que las mujeres. Esto es, cuando una mujer habla o escribe usando el plural inclusivo o el genérico femenino, esta práctica se puede interpretar como "otra de las tonterías, nimiedades o pérdidas de tiempo de las feministas" que sólo les interesa a

${ }^{40}$ Medina, José: Epistemology of Resistance, pp. 27 y ss. 
ellas. ${ }^{41}$ Sin embargo, cuando un varón usa el plural inclusivo o genérico femenino, esto se suele recibir con algo menos de indiferencia, quizás con algo de sorpresa o incluso inquietud, que puede llevar a más personas a pensar y plantearse el porqué de este uso. Esto no quiere decir que este uso ya esté aceptado o que vaya a dejar de recibir críticas o chistes. En el ejemplo que contemplamos anteriormente, cuando Pablo Iglesias se refirió a sí mismo como "una treintañera trabajadora", hubo muchísimos chistes y chanzas por tal uso; sin embargo, también se abrió un debate sobre la situación laboral de las mujeres en España que no se hubiera abierto si hubiera sido una mujer la que transformara así el lenguaje. Entonces, cuando los hombres aceptan y continúan este uso feminista del lenguaje, están reconociendo una problemática social (la discriminación de las mujeres) y poniendo las bases para intentar solucionarla (de nuevo, no sólo con transformaciones del lenguaje, sino con prácticas). Vemos, de nuevo, que los usos del lenguaje no se pueden dar por separado, para grupos cerrados, sino que necesitan una cierta aceptación social, sobre todo de los sectores epistémicamente más privilegiados, para que prosperen.

En conclusión, y en una vuelta de tuerca más al argumento en oposición al juego de lenguaje social: si el grupo que detenta autoridad epistémica entiende, acepta y continúa con la transformación crítica de la norma o del uso del lenguaje, propuesta por el grupo que tenía menor representación, este uso novedoso tiene más probabilidad de ser admitido y continuado que cuando el grupo con autoridad epistémica lo ningunea, ignora o ridiculiza. De modo similar, cuando una reivindicación no se sigue o resulta difícil de entender por gran parte de la población, sobre todo por la que ocupa posiciones de autoridad epistémica, será menos probable que este uso y las prácticas críticas que le acompañan se extiendan y prosperen. En esos casos, estas transformaciones del lenguaje sí se pueden entender como juegos de lenguaje sociales, cerrados

${ }^{41}$ Cabe recordar una polémica acaecida en España en 2008 cuando la Ministra de Igualdad, Bibiana Aído, usó los términos "miembros" y "miembras" para aludir a los componentes del Parlamento, causando hilaridad, chistes variados y comentarios despectivos de muchos sectores distintos (políticos y periodistas de derecha, representantes de la iglesia, lingüistas...). En este caso, como en tantos otros, la crítica feminista subyacente a esta transformación del lenguaje se disolvió entre el chiste y la anécdota. 
en sí, que pierden eficacia, capacidad de crítica y transformación, ya que no son comprendidos, ni convencen a los demás componentes de esta sociedad que se pretende transformar. Éste puede ser el caso de la reivindicación transfeminista explicada al final del apartado anterior: el colectivo mery sut ha transformado tanto el lenguaje, que sus reivindicaciones resultan prácticamente ininteligibles para quienes no formen parte de este grupo. Nos encontramos ante un posible caso de juego de lenguaje social, donde un grupo crea y modifica el lenguaje por cuenta propia, sin tener en cuenta a los demás hablantes de esa sociedad y, por ello, al faltarle regularidad o posibilidad de ser recibido y transformado por otras personas, se vacía de contenido y apenas puede ser entendido o disputado.

\section{Recapitulación y cierre}

A través de un estudio de varios ejemplos, mi intención ha sido analizar una interpretación de la obra de Wittgenstein, la que iguala juegos de lenguaje y formas de vida, reglas del juego y normas sociales, para evaluar su viabilidad, sus límites y sus efectos. Autores como José Medina, Miranda Fricker o Peg O'Connor han vinculado algunos elementos de la obra del segundo Wittgenstein con sus reivindicaciones a favor de las minorías y han propuesto una comprensión plural, cambiante y hasta conflictiva de los juegos de lenguaje y sus reglas, donde caben (y son bienvenidas) distintas interpretaciones de la misma norma, así como prácticas críticas y subversivas con las normas establecidas.

Resulta destacable, además, que, según esta comprensión, los lenguajes y las prácticas no son neutros, sino que están cargados de significaciones; tampoco son necesarios u obligatorios, sino convencionales y susceptibles de ser modificados o subvertidos y, por último, tampoco son únicos, cerrados o exclusivos, sino que están compartidos por seres humanos distintos.

Tras describir dicha comprensión de la obra de Wittgenstein, he buscado ejemplos que la favorecen (en las obras de O'Connor y Fricker), pero también posibles contraejemplos, como la diferenciación entre "huichol" y "wixarica" o la reivindicación feminista del plural inclusivo. Los análisis de estos ejemplos y contraejemplos me han llevado a formular dos tesis: primero, para modificar un uso del lenguaje y una práctica, ya se debe formar parte de ese juego de 
lenguaje y conocer sus reglas; $y$, segundo, estas modificaciones no pueden darse por separado, por parte de un grupo aislado, sino que necesitan que otros grupos (generalmente los de mayor influencia) entiendan, respeten y continúen estos nuevos usos. De este modo, lo que parecían ser contraejemplos al argumento del juego de lenguaje social siguen confirmando, en realidad, esta argumentación.

Los análisis de los ejemplos sirven como muestras, además, de que los lenguajes humanos no están separados de las prácticas, sino que estas dimensiones se dan de modo entrelazado y compartido, de tal modo que con los usos del lenguaje se puede influir o afectar a los demás. Además, también se ha constatado que no todos los grupos humanos tienen la misma capacidad de modificar el lenguaje y las prácticas, sino que unos ocupan posiciones de privilegio o autoridad epistémica, mientras que a otros les resulta más difícil visibilizar sus problemáticas o reciben, desde fuera (aunque no completamente desde fuera), usos del lenguaje y prácticas que los oprimen.

En conclusión, esta comprensión aplicada y política de la obra de Wittgenstein (aunque sea algo heterodoxa) proporciona herramientas conceptuales que facilitan el estudio o la reflexión sobre situaciones sociales actuales de opresión o de discriminación, por medio del lenguaje y de las prácticas, y da asimismo posibles vías de solución a estas problemáticas. Esto es, al considerar que las reglas del juego no son necesarias, sino convencionales y que quienes reciben usos del lenguaje ofensivos ya forman parte de ese juego de lenguaje y, por ello, ya lo pueden transformar y subvertir, se abren posibles recursos para diagnosticar y tratar de eliminar usos y prácticas ofensivas del lenguaje. 